\title{
GAMBARAN PENGETAHUAN IBU TENTANG ABORTUS DI WILAYAH KERJA PUSKESMAS LASEPANG KABUPATEN BANTAENG
}

\author{
Erniawati $^{1 *}$, Asriany, Lisdayanti, Sumarni, Jusni, Mudyawati Kamaruddin \\ ${ }^{1}$ Program Studi Kebidanan, Akademi Kebidanan Tahirah Al Baeti Bulukumba, Sulawesi Selatan \\ *Corresponding author: Telp: +6281343824649, email: erniawati@gmail.com
}

\begin{abstract}
ABSTRAK
Abortus adalah salah satu masalah kesehatan reproduksi yang perlu mendapatkan perhatian karena merupakan penyebab kematian wanita diseluruh dunia. Abortus merupakan pengeluaran hasil konsepsi sebelum usia kehamian mencapai 20 minggu. Abortus dapat disebabkan karena pengetahuan ibu yang kurang. Penyebab Angka Kematian Ibu yang paling sering adalah pendarahan. Seperti yang telah diketahui sebelumnya bahwa perdarahan merupakan komplikasi dari terjadinya abortus. Berdasarkan data dari puskesmas Lasepang, Kabupaten Bantaeng, dari tahun 2017 sampai tahun 2019 terdapat 71 kasus abortus yaitu sebanyak 21 abortus di tahun 2017, 28 abortus (2018) dan 21 abortus (2019) di wilayah kerja puskesmas Lasepang.Tujuan penelitian ini untuk mengetahui gambaran pengetahuan ibu tentang abortus di wilayah kerja Puskesmas Lasepang. Jenis penelitian yang digunakan adalah jenis penelitian deskriptif. Sampel dalam penelitian ini adalah ibu post abortus di wilayah kerja Puskesmas Lasepang Kabupaten Bantaeng sebanyak 71 orang. Berdasarkan hasil analisa data menunjukkan tidak ada responden yang berpengetahuan baik tentang abortus, yang berpengetahuan cukup sebanyak 12,5\%, dan yang berpengetahuan kurang sebanyak $87,5 \%$. Dari hasil penelitian tersebut, disimpulkan bahwa responden kebanyakan kurang pengetahuan tentang abortus.
\end{abstract}

Kata kunci : Abortus, Angka Kematian Ibu, Pengetahuan

\section{ABSTRACT}

Abortion is one of the issues of reproductive health that needs attention because it is a cause of death for women around the world. Abortion is the release of pregnancy prior to 20 weeks of gestation. Abortion may be caused by a lack of information on the part of the mother. Bleeding is the most common cause of maternal mortality. Bleeding is as previously known, a complication of abortion. Based on data from the Lasepang Health Centre, Bantaeng Regency, there were 71 abortion cases between 2017 and 2019, there were 21 abortions in 2017, 28 abortions (2018) and 21 abortions (2019) at the Lasepang Health Centre. The purpose of this study was to explain the mother's awareness of abortion in the work area of the Lasepang Health Centre. The purpose of this study was to explain the mother's awareness of abortion in the work area of the Lasepang Health Centre. The sample in this analysis was 71 postabortion mothers at the Lasepang Health Centre, Bantaeng District. Based on the findings of the data analysis, it was seen that no respondents had clear knowledge of abortion, $12.5 \%$ had adequate knowledge, and $87.5 \%$ had less knowledge. Based on the findings of this analysis, it was concluded that most of the respondents had no knowledge of abortion.

Keywords: Abortion, Awareness, Infant Mortality

\section{PENDAHULUAN}

Indonesia memiliki angka kematian ibu (AKI) yang masih tergolong tinggi diantara negaranegara Association of Southeast Asian Nation(ASEAN). Penyebab utama kematian ibu di Indonesia pada umumnya adalah komplikasi kehamilan/persalinan yaitu perdarahan (42\%), eklampsi/preeklampsi (13\%). Abortus (11\%), infeksi (10\%), partus lama/persalinan macet (9\%) dan penyebab lain (15\%). ${ }^{1,2}$ Menurut World Health Organisasi (WHO) abortus merupakan masalah kesehatan reproduksi yang perlu mendapatkan perhatian dan merupakan penyebab kematian 
waniita diseluruh dunia. Di negara berkembang, 90\% abortus terjadi secara tidak aman, sehingga berkontribusi $11 \%-13 \%$ terhadap kematian maternal ${ }^{3}$.

Menurut WHO (2015), diperkirakan 4,2 juta abortus dilakukan setiap tahun di ASEAN dengan perincian 1,3 juta dilakukan di Vietnam dan Singapura, 750.000-1.500.000 dilakukan di Indonesia, 155.000-750.000 dilakukan di Filidhina dan 300.000-900.000 dilakukan di Thailand. Laporan dari Australian Consortium For Indonesian Studies, bahwa hasil penelitian yang dilakukan di 10 kota besar dan 6 kabupaten di Indonesia menunjukkan terjadi 43 kasus aborsi per 100 kelahiran hidup (Purwaningrum \& Fibriana, 2017).

Kemenkes RI, 2015 menunjukkan presentase keguguran di Indonesia sebesar 4\% pada kelompok perempuan pernah kawin usia 10-59 tahun. Presentase kejadian abortus spontan di Indonesia berdasarkan kelompok umur yaitu $3,8 \%$ pada kelompok umur 15-19 tahun, 5,8\% pada kelompok umur 20-24 tahun, 5,8\% pada kelompok umur 2529 tahun dan 5,7 pada kelompok umur 30-34 tahun. Besarnya kemungkinan keguguran yanng terjadi pada wanita usia subur adalah $10 \%-25 \%$. Berdasarkan studi WHO satu dari setiap empat kehamilan berakhir dengan abortus.

Distribusi penyebab kematian ibu di Provinsi Sulawesi Selatan pada tahun 2014 karena perdarahan yang didalamnya termasuk kasus abortus karena dalam laporan hanya disebutkan perdarahan atau sepsis sebanyak 55 orang $(39,85 \%)$, infeksi sebanyak 3 orang $(2,17 \%)$, karena gangguan system peredaran darah sebanyak 2 kasus (1,44\%), dan karena penyebab lain sebanyak 34 kasus $(24,63 \%){ }^{4}$

Berdasarkan data Dinas Kesehatan (DINKES) Kabupaten, Bantaeng, pada tahun 2019 kasus abortus terdapat 79 orang yang mengalami abortus ${ }^{5}$.

Berdasarkan data dari puskesmas Lasepang, Kabupaten Bantaeng, dari tahun 2017 sampai tahun 2019 terdapat 71 kasus abortus yaitu pada tahun 2017 terdapat 21 abortus, tahun 2018 terdapat 28 abortus dan tahun 2019 terdapat 21 abortus di wilayah kerja puskesmas Lasepang.

\section{METODOLOGI}

Jenis penelitian yang digunakan adalah survey deskriftif,

Populasi dalam penelitian ini adalah Populasi dalam penelitian ini yaitu ibu yang mengalami abortus pada tahun 2017-2019 dengan jumlah 71 orang.

Teknik pengambilan sampel ini adalah accidental sampling. sebanyak 40 responden.

Jenis data yang dikumpulkan dalam penelitian ini adalah primer. Pengumpulan data primer dilakukan dengan cara mengisi lembar tes. Dalam penelitian ini adalah pengetahuan ibu tentang abortus.

Variabel yang digunakan dalam penelitian ini adalah variabel tunggal. Dalam penelitian ini yang menjadi variabel adalah pengetahuan dan abortus.

\section{HASIL DAN PEMBAHASAN}

1) Karakteristik Responden berdasarkan umur

Tabel 1 Distribusi frekuensi responden berdasarkan usia di wilayah kerja Puskesmas Lasepang Kab. Bantaeng Tahun 2020

\begin{tabular}{lll}
\hline Umur & $(\mathrm{f})$ & $(\%)$ \\
\hline $15-25$ & 12 & $30 \%$ \\
$26-35$ & 22 & $55 \%$ \\
$36-46$ & 6 & $15 \%$ \\
Total & 40 & $100 \%$ \\
\hline
\end{tabular}

Sumber : Data Primer Tahun 2020

Berdasarkan tabel 1 di atas diketahui bahwa jumlah responden yang memiliki usia antara 15-25 tahun adalah 12 orang (30\%), jumlah responden yang memiliki usia antara 26-35 tahun adalah 22 orang (55 \%), dan jumlah responden yang memiliki usia antara 36-46 adalah 6 orang $(15 \%$.)

Berdasarkan data tersebut dapat digambarkan bahwa jumlah responden yang paling banyak dalam penelitian ini adalah ibu dengan usia 26-35 tahun yaitu sebanyak 22 orang $(55 \%$.)

Tabel 2 Distribusi frekuensi berdasarkan pekerjaan di wilayah kerja Puskesmas Lasepang, Kab. Bantaeng tahun 2020

\begin{tabular}{lll}
\hline Pekerjaan & Frekuensi(f) & presentase \\
\hline PNS & 5 & $12 \%$ \\
Honorer & 13 & $32 \%$ \\
IRT & 22 & $55 \%$ \\
Total & 40 & $100 \%$ \\
\hline
\end{tabular}

Sumber : Data Primer Tahun 2020 
Berdasarkan tabel 2 di atas diketahui bahwa jumlah responden yang bekerja sebagai PNS sebanyak 5 orang $(12 \%)$ jumlah responden yang bekerja sebagai honorer sebanyak 13 orang (32\%), dan jumlah responden yang bekerja sebagai IRT sebanyak 22 orang $(55 \%)$.

Tabel 3 Distribusi frekuensi responden berdasarkan pengetahuan ibu di wilayah kerja Puskesmas Lasepang, KabupatenBantaeng tahun 2020

\begin{tabular}{lll}
\hline $\begin{array}{l}\text { Pengetahuan } \\
\text { ibu }\end{array}$ & Frekuensi (f) & $\begin{array}{l}\text { Presentase } \\
(\%)\end{array}$ \\
\hline Baik & 0 & $0 \%$ \\
Cukup & 5 & $12,5 \%$ \\
Kurang & 35 & $87,5 \%$ \\
Total & 40 & $100 \%$ \\
\hline
\end{tabular}

Sumber : Data Primer Tahun 2020

Berdasarkan tabel 3 di atas diketahui bahwa tidak ada responden yang mempunyai pengetahuan baik tentang abortus, jumlah responden yang mempunyai pengetahuan cukup sebanyak 5 orang $(12,5 \%)$, dan jumlah responden yang mempunyai pengetahuan kurang sebanyak 35 orang $(87,5 \%)$.

Berdasarkan data tersebut dapat digambarkan bahwa responden pada penelitian ini di wilayah kerja puskesmas Lasepang Kabupaten Bantaeng mempunyai pengetahuan yang sangat kurang.

\section{PEMBAHASAN}

Abortus adalah pengeluaran hasil konsepsi sebelum waktunya. Abortus dapat disebabkan karena pengetahuan ibu yang kurang. Pengetahuan yang dimaksud salah satunya mikroorganisme penyebab infeksi pada kandungan sehingga dapat terjadi abortus. ${ }^{6}$ Penyebab Angka Kematian Ibu (AKI) yang paling sering adalah pendarahan. Seperti yang telah diketahui sebelumnya bahwa pendarahan merupakan komplikasi dari terjadinya abortus.

Notoadmodjo (2014), mengemukakan pengetahuan adalah hasil pengindraan manusia atau hasil tahu seseorang terhadap suatu objek melalui panca indra manusia guna pengindraan terhadap objek yakni penglihatan, pendengaran, penciuman, rasa dan perabaan pada waktu pengindraan untuk menghasilkan pengetahuan tersebut dipengaruhi oleh intensitas perhatian dan persepsi terhadap objek. Pengetahuan seseorang sebagian besar diperoleh melalui indra pendengaran dan indra penglihatan ${ }^{7}$.

Berdasarkan hasil penelitian jumlah responden yang mempunyai pengetahuan cukup yaitu 5 orang $(12,5 \%)$. Responden yang memiliki pengetahuan cukup memiliki kemampuan yang belum maksimal dalam memahami kejadian abortus, hal ini terjadi karena informasi tentang abortus yang didapatkan masih kurang. Informasi yang responden dapatkan mengenai abortus dapat terjadi karena kurangnya minat responden dalam menggali lebih jauh tentang hal-hal yang berhubungan dengan kejadian abortus. Hal ini dapat dipengaruhi oleh rendahnya minat dan tingkat kesibukan responden dalam mencari tahu informasi.

Sedangkan jumlah responden yang mempunyai pengetahuan kurang adalah 35 orang $(87,5 \%)$, hal ini disebabkan oleh kurangnya minat responden dalam menggali lebih jauh tentang bahaya abortus serta kurang mendapatkan informasi dan pengalaman dari teman-teman dan dari petugas kesehatan sehingga menyebabkan banyak responden yang tidak tahu dan kurang memiliki pengetahuan tentang abortus.

Berdasarkan hasil penelitian yang di lakukan di wilayah kerja Puskesmas Lasepang Kabupaten Bantaeng, bahwa responden yang paling dominan berdasarkan pengetahuan lebih banyak yang memiliki pengetahuan yang kurang tentang abortus yaitu sebanyak 35 orang $(87,5 \%)$ dan tidak ada responden yang mempunyai pengetahuan baik tentang abortus. Karena responden mengangap bahwa kejadian abortus tidak terlalu berpengaruh terhadap kesehatan ibu dan mereka menganggap kejadian tersebut adalah peristiwa yang terjadi secara keturunan sehingga responden tidak menghiraukan informasi-informasi yang berkaitan dengan kejadian abortus.

Hasil penelitian diatas sejalan dengan teori yang dikemukakan oleh Nugroho (2015), pengetahuan atau kognitif merupakan domain yang sangat penting dalam membentuk tindakan seseorang. Dari pengalaman dan penelitian terbukti bahwa perilaku yang didasari oleh pengetahuan akan lebih langgeng dari pada perilaku yang tidak didasari oleh pengetahuan. ${ }^{8}$

Penelitian ini sejalan dengan penelitian Nunung Fitri Ulandari (2015), menyatakan bahwa pengetahuan tentang abortus dapat dipengaruhi oleh kurangnya informasi yang didapatkan dari tenaga kesehatan, dan dipengaruhi oleh kesibukan sehari-hari. Dari 30 responden yang pengetahuan baik yaitu 5 orang $(16,7 \%)$, pengetahuan cukup 
sebanyak 6 orang (20\%), dan pengetahuan kurang sebanyak 19 orang $(63,3 \%)$.

Namun penelitian ini tidak sejalan dengan penelitian yang dilakukan oleh Lilis Pra Utari (2013), dari 68 responden, yang mempunyai pengetahuan baik yaitu sebanyak 16 orang (23,6 $\%)$, responden yang mempunyai pengetahuan cukup yaitu 41 orang $(60,3 \%)$, dan responden yang mempunyai pengetahuan kurang yaitu 11 orang $(16,1 \%)$, dari hasil penelitian Lilis Pra Utari lebih banyak yang berpengetahuan cukup yaitu 41 orang $(60,3 \%)$

Pengetahuan tentang abortus sangat membantu ibu dalam memahami tentang abortus. Sehingga perlu diupayakan agar ibu selalu diberikan pendidikan kesehatan melalui penyuluhan maupun dengan cara yang lain agar pengetahuan ibu dapat bertambah dan faktor risiko abortus dapat dikurangi.

\section{KESIMPULAN}

Berdasarkan hasil penelitian yang telah dilakukan tentang "Gambaran pengetahuan ibu tentang abortus di wilayah kerja Puskesmas Lasepang, Kab.Bantaeng tahun 2020”, dapat disimpulkan bahwa responden pada penelitian ini lebih banyak yang memiliki pengetahuan yang kurang tentang abortus yaitu dari 40 responden terdapat 35 responden $(87,5 \%)$ yang memiliki pengetahuan kurang tentang abortus.

\section{DAFTAR PUSTAKA}

1. Erniawati, Kamaruddin M. Asuhan Kebidanan Pasca Salin. 1st ed. Manggu Makmur Tanjung Lestari; 2020. https://penerbitmanggu.co.id/

2. Kamaruddin M, Asriany A, Kasmawati, Triananinsi N. Kajian Pengetahuan Ibu Hamil tentang Bahaya Asap Rokok pada kehamilan di Puskesmas Herlang Kabupaten Bulukumba. 2020;2(2):192-196.

3. World Health Organization. Angka Kematian Ibu. Published online 2015. www.searo.who.int/indoneisa.com

4. Dinas Kesehatan Kabupaten Bulukumba. Profil Kesehatan Kabupaten Bulukumba Tahun 2014. Published online 2015.

5. Kementerian Kesehatan RI Badan Litbangkes. Laporan Kinerja Litjen Kesehatan Masyarakat. Published online 2016.

6. Kamaruddin M. Trik Pencegahan dan Mengatasi TORCH pada Ibu dan Bayi Melalui Natural Products. Published online March
2019.

https://www.researchgate.net/publication/3341

93275_TRIK_PENCEGAHAN_DAN_MENG ATASI_TORCH_PADA_IBU_DAN_BAYI_ MELALUI_NATURAL_PRODUCTS

7. Notoatmodjo S. Metodologi Penelitian Kesehatan. Rineka Cipta; 2014.

8. Nugroho T, Utama BI. Masalah Kesehatan Reproduksi Wanita. Nuha Medika; 2014. 